\title{
ANALISIS PENGARUH MOTIVASI PELAYANAN PUBLIK (PUBLIC SERVICE MOTIVATION) GURU DAN TENAGA KEPENDIDIKAN DI KECAMATAN PARUNGKUDA - SUKABUMI
}

\author{
Suanah1) \\ Gorky Sembiring2) \\ Yufiarti3) \\ 1) Mahasiswa S2 Magister Pendidikan Dasar (MPDr) Universitas Terbuka \\ 2) Dosen Magister Pendidikan Dasar (MPDr) Universitas Terbuka \\ 3) Dosen Tuton Magister Pendidikan Dasar (MPDr) Universitas Terbuka \\ e-mail: suanah124@gmail.com
}

\begin{abstract}
The purpose of this study is to measure the extent to which teachers and education personnel have the motivation of public services and to determine the factors that become obstacles and drivers for teachers and education personnel to implement values in the motivation of public services. The sample of respondents was determined as many as 22 people who were distributed into 6 schools. Data collection methods were carried out by direct observation in schools, interviews with respondents and through field surveys with questionnaires. Data processing using SPSS software and statistical analysis is done by testing the research hypothesis to examine the relationship between variables and solve research problems. The results of the study are based on hypothesis testing, namely that there is an effect of mentality on service motivation while performance has no effect on service motivation. Simultaneously mentality and performance affect the motivation of public services by $62.0 \%$. The factor that is driving the implementation of values in the motivation of public services is the level of teacher education, personality, dedication, ability and discipline, while the inhibiting factor comes from internal factors that come from within the teacher itself.
\end{abstract}

Keywords: Mentality, Performance, Motivation, Public Service.

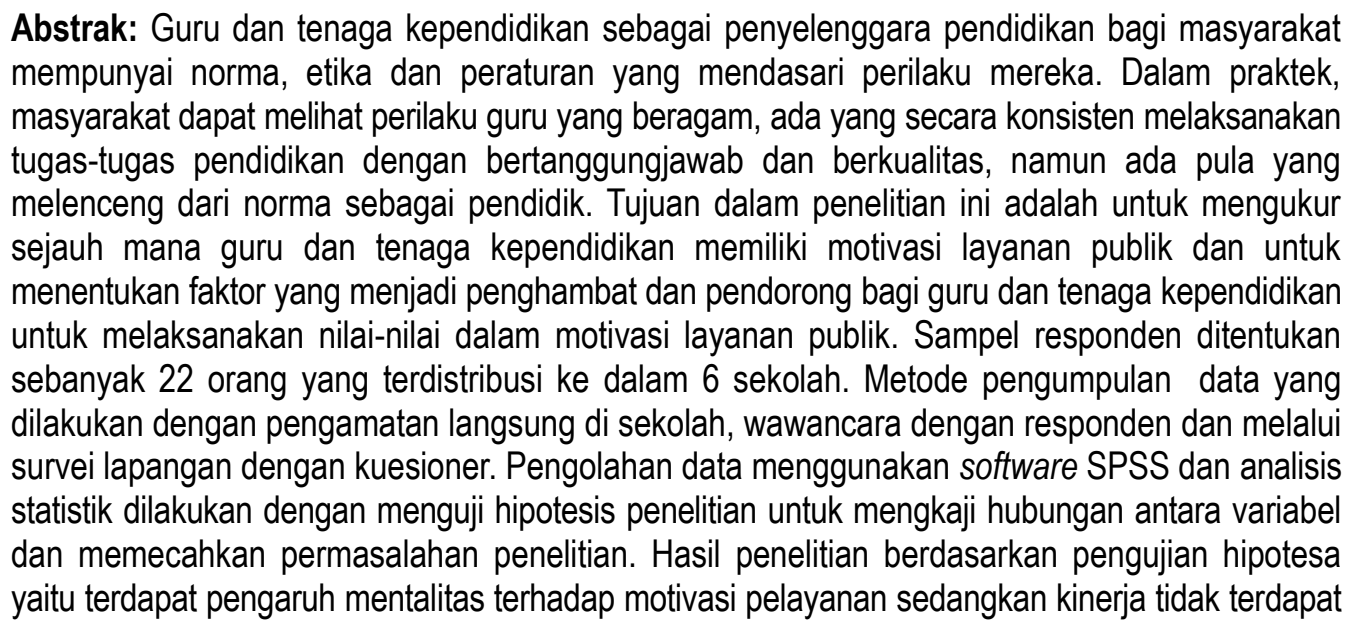


pengaruhterhadap motivasi pelayanan. Secara simultan mentalitas dan kinerja berpengaruh terhadap motivasi layanan publik sebesar $62,0 \%$. Faktor yang menjadi pendorong untuk melaksanakan nilai-nilai dalam motivasi layanan publik yaitu tingkat pendidikan guru, kepribadian, dedikasi, kemampuan dan kedisiplinan, sedangkan faktor penghambat berasal dari faktor internal yang berasal dari dalam guru itu sendiri.

Kata kunci: Mentalitas, Kinerja, Motivasi, Pelayanan Publik.

\section{PENDAHULUAN}

Keberhasilan suatu sekolah tidak terlepas dari manajemen sumber daya manusia yang dimiliki, antara lain adalah kinerja mereka dalam melayani masyarakat yang berada dalam lingkungan sekolah. Guru dan tenaga kependidikan sebagai pelaksana pendidikan bagi masyarakat mempunyai norma, etika dan peraturan yang mendasari perilaku yang selaras dengan azas-azas profesional, dengan dilandasi semangat mendidik dan mencerdaskan anak bangsa. Dalam kegiatan di masyarakat, khalayak dapat melihat perilaku guru yang beragam, ada yang konsisten melaksanakan tugas pendidikan dengan bertanggungjawab dan berkualitas, namun ada pula yang melenceng dari norma sebagai pendidik.

Faktor strategis dalam layanan publik akan ditentukan oleh kinerja yang diberikan oleh guru dan tenaga kependidikan dalam melaksanakan tugas yang dibebankan kepadanya didasarkan atas kecakapan, pengalaman dan kesungguhan dalam waktu tertentu. Dengan demikian betapa pentingnya motivasi guru dan tenaga kependidikan dalam memberikan pelayanan publik dalam melaksanakan tugas dan tanggungjawabnya. Oleh karena itu penelitian ini bertujuan untuk menganalisis pengaruh motivasi pelayanan publik (public service motivation) guru dan tenaga kependidikan dan mengetahui faktor yang menjadi penghambat atau pendorong bagi guru melaksanakan nilai-nilai dalam motivasi layanan publik dalam tugas pekerjaannya.

Konsep motivasi pelayanan publik (public service motivation) diawali oleh James L. Perry. Konsep ini bersifat multi dimensi, mencakup norma, etika dan emosi yang menarik minat seseorang pada pekerjaan yang berhubungan dengan memberikan layanan (service) kepada masyarakat, termasuk memberikan layanan pendidikan. Komitmen kepada kepentingan masyarakat, empati dan kesediaan untuk berkorban merupakan dimensi motivasi layanan publik. Menurut Moenir (2008) dalam Hardiansyah (2011:18) mengemukakan bahwa pelayanan publik adalah kegiatan yang dilakukan seseorang dengan landasan faktor material melalui sistem, prosedur dan metode tertentu dalam usaha memenuhi kepentingan orang lain sesuai dengan haknya.

Hasibuan (2007) berpendapat, motivasi memiliki tujuan untuk meningkatkan moral dan kepuasan kerja, kedisiplinan, loyalitas, produktivitas kerja, kreativitas dan partisipasi, mempertahankan kestabilan, menciptakan suasana dan hubungan kerja yang baik, meningkatkan tingkat kesejateraan dan mempertinggi rasa tanggung jawab terhadap tugas-tugasnya.

Motivasi juga didefinisikan sebagai kesediaan atau upaya untuk melaksanakan tujuan organisasi secara maksimal, yang dikondisikan oleh kemampuan upaya tersebut 
untuk memenuhi suatu kebutuhan individual (Robbin, 1996). Malayu (2007) menyatakan motivasi adalah pemberian daya penggerak yang menciptakan kegairahan kerja seseorang agar mereka mau bekerja sama, bekerja efektif dan terintegrasi dengan segala daya upayanya dalam mencapai kepuasan. Di sisi lain Marliani (2015) mendefinisikan motivasi kerja sebagai dorongan dari dalam diri individu untuk melaksanakan sebuah pekerjaan karena mereka memiliki keinginan untuk melakukannya serta bertujuan untuk mencapai tujuan yang diinginkan.

Kinerja adalah hasil kerja yang dapat dicapai oleh seseorang dalam organisasi, sesuai dengan wewenang dan tanggung jawabdalam mencapai tujuan organisasi bersangkutan secara legal, tidak melanggar hukum dan sesuai dengan moral maupun etika (Prawirosentono, 1997). Sedangkan Michael Armstrong (2004) menyatakan kinerja adalah hasil yang diperoleh organisasi selama satu periode sebagai hasil pekerjaan yang mempunyai hubungan kuat dengan tujuan atau strategi suatu lembaga. Kinerja adalah gambaran mengenai tingkat pencapaian pelaksanaan kegiatan dalam mewujudkan sasaran, tujuan, misi dan visi organisasi yang tertuang dalam perumusan skema strategi (strategic planning) suatu lembaga atau organisasi (Indra Bastian, 2001). Kinerja sebagai efektivitas secara menyeluruh untuk memenuhi kebutuhan yang ditetapkan dari setiap kelompok berkenaan dengan usaha yang sistematik dan meningkatkan kemampuan lembaga secara terus menerus mencapai kebutuhannya secara efektif (Chaizi,2004).

Menurut Waluyo (2013) motivasi kerja ialah sebuah dorongan atau semangat untuk melaksanakan pekerjaan. Konsep motivasi kerja adalah suatu proses yang mendorong seseorang menggunakan kemampuan sepenuhnya untuk melakukan tugasnya. Komitmen dalam diri seseorang atas kewajiban terhadap organisasi dilandasi adanya komitmen yang kuat untuk melakukannya (Bachroni, 1985).

Untuk mewujudkan tujuan suatu lembaga agar bisa menerapkan konsep kinerja yang berkualitas dan profesional maka perlu kita pahami apa yang harus menjadi tujuan dari kinerja, tujuan kinerja untuk menumbuhkan budaya individu bertanggungjawab atas kelanjutan peningkatan proses bisnis dan peningkatan keterampilan dan konstribusi mereka sendiri (Irham Fahmi, 2013). Menurut Liosten (2014) Kegunaan penilain kinerja bagi organisasi, antara lain peningkatan kinerja, penyesuaian kompetensi, keputusan penempatan, kebutuhan pelatihan dan pengembangan dan menganalisis kesalahan dalam desain pekerjaan.

Dalam kontek berorganisasi, komitmen didefinisikan sebagai kekuatan relatif individu dalam melibatkan dirinya dengan lembaga pendidikan. Menurut Boyle (1997), komitmen dapat dikarakteristikkan dalam tiga dimensi, yaitu keyakinan yang kuat akan misi dan tujuan organisasi, kemauan untuk berkorban demi tujuan organisasi dan memiliki keinginan membina hubungan jangka panjang dengan organisasi. Komitmen organisasional sebagai ukuran kekuatan identifikasi karyawan dengan tujuan dan nilai organisasi serta terlibat di dalamnya, komitmen oganisasi juga menjadi indikator yang lebih baik bagi karyawan yang ingin tetap pada pekerjaannya atau ingin pindah (McNeese Donna, 1993). Keterlibatan dan kesetiaan dipengaruhi oleh seberapa besar pekerjaan yang dibebankan sesuai dengan harapan mereka (Babakus, et. al, 1996). 
Pelayanan merupakan aspek yang sangat penting dan menentukan kualitas jasa yang dihasilkan. Agar dapat tampil dalam suasana yang kompetitif, organisasi harus berusaha meningkatkan kualitas pelayanannya sebagai strategi memenangkan persaingan. Dengan demikian, pelayanan publik dapat diartikan sebagai pemberian layanan (melayani) keperluan orang atau masyarakat yang mempunyai kepentingan pada organisasi itu sesuai dengan aturan pokok dan tata cara yang telah ditetapkan. Sementara itu, kondisi masyarakat saat ini telah terjadi suatu perkembangan yang sangat dinamis, tingkat kehidupan masyarakat yang semakin baik, merupakan indikasi dari empowering yang dialami oleh masyarakat (Thoha, 2009).

Mentalitas guru dan kinerjanya merupakan salah satu faktor strategis dalam layanan publik untuk mencapai kesejahteraan masyarakat, dan nilai-nilai baik yang dikandung dalam motivasi untuk melayani masyarakat, seperti peduli dengan apa yang terjadi di lingkungannya, bersedia berkorban dan tidak hanya memikirkan kepentingan dan keuntungan diri sendiri, tidak suka dengan watak negatif seperti korupsi, nepotisme, dan sebagainya, serta perlu menjadi bagian kesadaran dan perilaku setiap orang yang bergerak dalam pendidikan.

\section{METODE PENELITIAN}

Penelitian ini adalah penelitian eksploratif asosiatif yang bertujuan untuk menggambarkan keadaan atau status fenomena yang berhubungan motivasi pelayanan publik yang diberikan oleh guru dan tenaga kependidikan dan untuk mengetahui pengaruh mentalitas dan kinerja guru terhadap motivasi pelayanan publik. Pengambilan data dilakukan dengan pengamatan langsung di sekolah, wawancara dengan responden dan kuesioner yang berisi sejumlah pertanyaan tertulis yang diberikan kepada responden untuk diisi sesuai dengan keadaan yang sebenarnya.

Populasi dalam penelitian ini adalah guru dan tenaga kependidikan yang tersebar di 24 sekolah dalam wilayah kecamatan Parungkuda kabupaten Sukabumi, Jawa Barat. Sedangkan sampel responden ditentukan sebanyak 22 orang yang terdistribusi ke dalam 6 sekolah. Instrumen penelitian berupa kuesioner yang telah disediakan jawaban sehingga responden tinggal memilih salah satu jawaban yang tersedia, setiap pertanyaan terdiri dari lima alternatif jawaban, perhitungan skor penilaian jawaban responden dengan rentang skor 0-5. Pengolahan data menggunakan SPSS dalam analisis regresi, untuk mengkaji interaksi antara variabel bebas mentalitas $\left(X_{1}\right)$ dan kinerja guru $\left(X_{2}\right)$ dengan variabel terikat motivasi pelayanan publik $(Y)$.

Metode analisis datadilakukan untuk seluruh instrument yang terdapat pada data kuesioner terlebih dahulu dilakukan uji validitas dan uji reliabilitas dengan menggunakan Program software SPSS. Pengujian instrument penelitian dalam data kuesioner harus memenuhi syarat valid dan reliable yang bertujuan untuk memudahkan dalam perhitungan data dan memiliki tingkat keakurasian tinggi untuk menghasilkan kesimpulan yang dapat dipertanggungjawabkan.

Analisis statistik inferensial dilakukan berkaitan dengan metode dalam penarikkan kesimpulan berdasarkan data yang diperoleh dari sampel penelitian yang digunakan untuk menggambarkan karakteristik atau ciri dari suatu populasi, sehingga 
penggunaan analisis statistik inferensial disebut juga statistik induktif atau statistik penarikkan kesimpulan. Pada statistik inferensial biasanya dilakukan pengujian hipotesis dan pendugaan mengenai karakteristik (ciri) dari suatu populasi. Statistik inferensial digunakan untuk menguji taraf signifikansi misalnya uji T pada tabel T, uji $F$ pada tabel $F$ (Sugiyono, 2004).

\section{TEMUAN DAN PEMBAHASAN}

\section{Analisis Data Pengujian}

Berdasarkan analisis data dari output SPSS, maka data nilai rata-rata untuk seluruh butir pertanyaan dalam kuesioner yaitu dari jumlah sampel $(N)=22$ orang, diperolehcnilai rata-rata (mean) tertinggi pada butir pertanyaan no. 15 sebesar 4,77, mengindikasikan bahwa responden mempunyai pemahaman untuk melakukan perubahan dalam masyarakat melalui pendidikan merupakan hal yang penting. Sedangkan nilai rata-rata terendah pada pertanyaan no. 17 sebesar 1,95, mengindikasikan bahwa responden berpendapat menghasilkan banyak uang bukan sesuatu yang lebih penting daripada memberikan pelayanan publik dalam kegiatan pembelajaran.

Uji validitas ini dilakukan dengan mengkorelasikan masing-masing skor item dengan skor total. Pengukuran validitas instrument diperoleh Correlations Statistic pada Sig. (1-tailed) $<0,05$, dapat disimpulkan butir pertanyaan pada instrument penelitian berkategori valid. Uji reliabilitas yang digunakan adalah metode Cronbach's Alpha, data uji reliabilitaspada Tabel 1.

Tabel 1. Uji Realibilitas

\begin{tabular}{ccc}
\hline & Reliability Statistics & \\
\hline Cronbach's Alpha & $\begin{array}{c}\text { Cronbach's Alpha Based } \\
\text { on Standardized Items }\end{array}$ & N of Items \\
\hline 0,846 & 0,867 & 20 \\
\hline
\end{tabular}

Sumber data: output SPSS Analyze Scale Reliability Analysis

Interpretasi uji reliabilitas dari output SPSS data pada Cronbach's Alpha 0,846 $>0,60$. Dapat disimpulkan bahwa butir pertanyaan pada instrumen penelitian berkategori reliable, dengan tingkat derajat realibilitas sangat tinggi.

Tabel 2. Pengujian Hipotesis H1 dan H2 Dengan Uji-t

\begin{tabular}{|c|c|c|c|c|c|c|}
\hline \multicolumn{7}{|c|}{ Coefficients $^{a}$} \\
\hline & \multirow[t]{2}{*}{ Model } & \multicolumn{2}{|c|}{ Unstandardized Coefficients } & \multirow{2}{*}{$\begin{array}{c}\text { Standardized } \\
\text { Coefficients } \\
\text { Beta }\end{array}$} & \multirow[t]{2}{*}{$t$} & \multirow[t]{2}{*}{ Sig. } \\
\hline & & B & Std. Error & & & \\
\hline \multirow{3}{*}{1} & (Constant) & 11,856 & 6,579 & & 1,802 & 0,087 \\
\hline & MENTALITAS (X1) & 1,533 & 0,336 & 0,680 & 4,560 & 0,000 \\
\hline & KINERJA (X2) & 0,515 & 0,324 & 0,237 & 1,591 & 0,128 \\
\hline
\end{tabular}

a. Dependent Variable: MOTIVASI PELAYANAN $(\mathrm{Y})$

Sumber data: output SPSS Analyze Regession Linear 
Analisis regresi berganda dengan pengujian Hipotesis $\mathrm{H} 1$ dan $\mathrm{H} 2$ dengan Uji-t, berdasarkan data dari output SPSS, maka data uji-t, dapat dilihat pada Tabel 2 dan kurva Uji-t pada Gambar 1.

Pengujian Hipotesis $(\mathrm{H} 1)$ diketahui nilai sig. untuk pengaruh $\mathrm{X} 1$ terhadap $\mathrm{Y}$ sebesar $0,000<0,05$ dan nilai $t$ hitung 4,560 $>t$ tabel 2,093, sehingga dapat disimpulkan bahwa $\mathrm{H} 1$ diterima yang berarti terdapat pengaruh $\mathrm{X} 1$ terhadap $\mathrm{Y}$. Pengujian Hipotesis $(\mathrm{H} 2)$ nilai sig. untuk pengaruh $X 2$ terhadap $Y$ sebesar $0,128>$ 0,05 dan nilai $t$ hitung 1,591< $\mathrm{t}$ tabel 2,093, sehingga dapat disimpulkan bahwa $\mathrm{H} 2$ ditolak yang berarti tidak terdapat pengaruh $\mathrm{X} 2$ terhadap $\mathrm{Y}$.

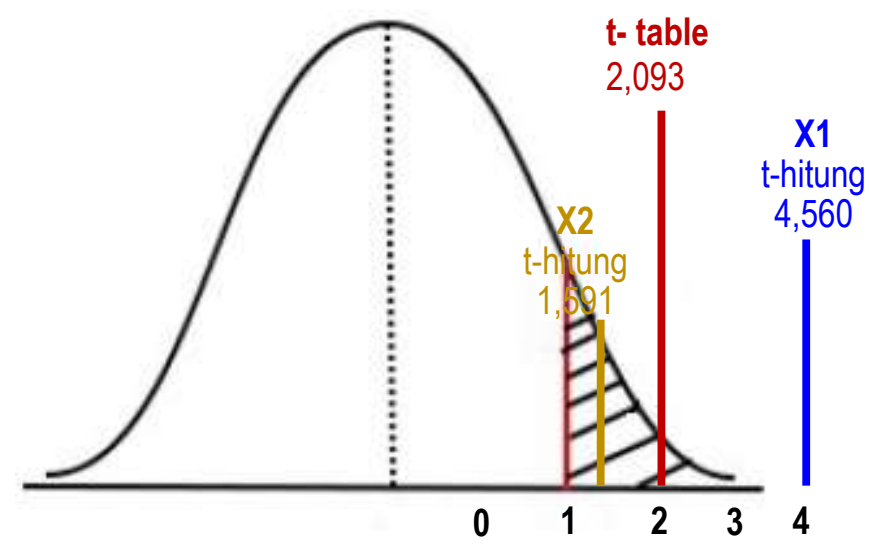

Gambar 1. Kurva Uji-t

Analisis regresi berganda dengan pengujian hipotesis $\mathrm{H} 3$ dengan uji $F$, berdasarkan data dari output SPSS, maka data uji-F, dapat dilihat pada Tabel 3.

Tabel 3. Pengujian Hipotesis H3 Dengan Uji-F

\begin{tabular}{|l|c|c|c|c|c|c|}
\hline \multicolumn{7}{|c|}{ ANOVA $^{\mathrm{b}}$} \\
\hline \multicolumn{2}{|c|}{ Model } & Sum of Squares & df & Mean Square & F & Sig. \\
\hline \multirow{3}{*}{1} & Regression & 229.712 & 2 & 114.856 & 15,515 & $0,000^{\mathrm{a}}$ \\
\cline { 2 - 7 } & Residual & 140.652 & 19 & 7.403 & & \\
\cline { 2 - 7 } & Total & 370.364 & 21 & & & \\
\hline
\end{tabular}

Sumber data: Output SPSS Analyze Regession Linear

Interpretasi uji-F dari output SPSS pada Tabel 3 menunjukan bahwa nilai signifikansi untuk pengaruh $\mathrm{X} 1$ dan $\mathrm{X} 2$ secara simultan terhadap $\mathrm{Y}$ adalah sebesar $0,000<0,05$ dan nilai $\mathrm{F}$ hitung $15,515>\mathrm{F}$ tabel $\mathbf{3 , 4 9}$, sehingga dapat disimpulkan H3 
diterima yang berarti terdapatpengaruh $\mathrm{X} 1$ dan $\mathrm{X} 2$ secara simultan terhadap $\mathrm{Y}$. Data koefisien diterminasi untuk nilai persentase pengaruh variabel $X 1$ dan $X 2$ secara simultan terhadap $Y$ dapat dilihat pada nilai $R$ square pada Tabel 4.

Tabel 4. Data Koefisien Diterminasi

\begin{tabular}{|c|c|c|c|c|}
\hline \multicolumn{4}{|c|}{ Model Summary } \\
\hline Model & R & R Square & Adjusted $R$ Square & Std. Error of the Estimate \\
\hline 1 & $0,788^{\mathrm{a}}$ & 0,620 & 0,580 & 2,721 \\
\hline \multicolumn{5}{|c|}{ a. Predictors: (Constant), KINERJA (X2), MENTALITAS (X1) } \\
\hline
\end{tabular}

Sumber data: Output SPSS Analyze Regession Linear)

Interpretasi dari output SPSS pada Tabel 4, diketahui nilai $\mathrm{R}$ Square sebesar 0,620 , hal ini mengandung arti bahwa pengaruh variabel X1 dan X2 secara simultan terhadap Y sebesar 62,0\%.

Analisis korelasi pearson variable $\mathrm{X} 1$ dan $\mathrm{Y}$ untuk mengetahui tingkat keeratan dan menentukan derajat hubungan antara variabel mentalitas (X1) dan motivasi pelayanan (Y) apakah bersifat positif atau negatif. Berdasarkan data dari output SPSS dapat dilihat pada Tabel 5.

Tabel 5. Analisis Korelasi Pearson Variable X1 dan Y

\begin{tabular}{|c|c|c|c|}
\hline \multicolumn{4}{|c|}{ Correlations } \\
\hline \multirow{3}{*}{ MENTALITAS (X1) } & MENTALITAS (X1) & MOTIVASI PELAYANAN (Y) \\
\cline { 2 - 4 } & Pearson Correlation & 1 & $0,755^{* *}$ \\
\cline { 2 - 4 } & Sig. (2-tailed) & & 0,000 \\
\cline { 2 - 4 } & $\mathrm{N}$ & 22 & 22 \\
\hline $\begin{array}{c}\text { MOTIVASI } \\
\text { PELAYANAN (Y) }\end{array}$ & Pearson Correlation & $0,755^{* *}$ & 1 \\
\cline { 2 - 4 } & Sig. (2-tailed) & 0,000 & 22 \\
\cline { 2 - 4 } & $\mathrm{N}$ & 22 & \\
\hline \multirow{2}{*}{ **. Correlation is significant at the 0.01 level (2-tailed). } \\
\hline
\end{tabular}

Sumber data: Output SPSS Analyze Correlate Bivariate

Interpretasi analisis korelasi pearson variable X1 dan Y dari output SPSS pada Tabel 5, diketahui bahwa nilai Sig. (2-tailed) $=0,000<0,05$, maka dapat dinyatakan antara variabel X1 dan $Y$ berkorelasi. Nilai Pearson correlation $=0,755$, maka dapat disimpulkan antara variabel $\mathrm{X} 1$ danY mempunyai derajat hubungan korelasi kuat dengan jenis hubungan bersifat positif.

Analisis korelasi pearson variable $\mathrm{X} 2$ dan $\mathrm{Y}$ untuk menentukan derajat hubungan antara variabel kinerja guru $(\mathrm{X} 2)$ dan motivasi pelayanan $(\mathrm{Y})$ apakah bersifat positif atau negatif. Berdasarkan data dari output SPSS dapat dilihat pada Tabel 6. 
Tabel 6. Analisis Korelasi Pearson Variable X2 dan Y

\begin{tabular}{|c|c|c|c|}
\hline \multicolumn{4}{|c|}{ Correlations } \\
\hline & & $\begin{array}{c}\text { KINERJA } \\
\text { (X2) }\end{array}$ & $\begin{array}{c}\text { MOTIVASI PELAYANAN } \\
\text { (Y) }\end{array}$ \\
\hline \multirow{2}{*}{$\begin{array}{c}\text { KINERJA } \\
\text { GURU } \\
\text { (X2) }\end{array}$} & Pearson Correlation & 1 & $0,452^{*}$ \\
\cline { 2 - 4 } & Sig. (2-tailed) & & 0,035 \\
\cline { 2 - 4 } & $\mathrm{N}$ & 22 & 22 \\
\hline $\begin{array}{c}\text { MOTIVASI } \\
\text { PELAYANAN } \\
\text { (Y) }\end{array}$ & Pearson Correlation & $0,452^{*}$ & 1 \\
\cline { 2 - 4 } & Sig. (2-tailed) & 0,035 & \\
\cline { 2 - 4 } & $\mathrm{N}$ & 22 & 22 \\
\hline \multirow{2}{*}{. Correlation is significant at the 0,05 level (2-tailed). } \\
\hline
\end{tabular}

Sumber data: Output SPSS Analyze Correlate Bivariate

Interpretasi analisis korelasi pearson variable $\mathrm{X} 2$ dan $\mathrm{Y}$ dari output SPSS diatas, diketahui bahwa nilai Sig. (2-tailed) $=0,035<0,05$, maka dapat dinyatakan antara variabel $\mathrm{X} 2$ dan $\mathrm{Y}$ berkorelasi. Nilai Pearson correlation $=0,452$, maka dapat disimpulkan antara variabel $\mathrm{X} 2$ dan $\mathrm{Y}$ mempunyai derajat hubungan korelasi sedang dengan jenis hubungan bersifat positif.

\section{Analisis Faktor Pendukung dan Penghambat}

Faktor pendukung bagi guru dan tenaga kependidikan untuk melaksanakan nilai-nilai dalam motivasi layanan publik dalam tugas pekerjaannya ada beberapa faktor yaitu tingkat pendidikan sebagai guru yang profesional, sehingga dalam mewujudkan kinerja yang profesional sebagai seorang guru dapat berjalan dengan maksimal. Kepribadian salah satu faktor yang sangat penting dalam mewujudkan kinerja yang profesional karena dalam kepribadian seorang guru akan tercermin dalam kegiatan belajar mengajar. Dedikasi tidak dapat dipisahkan dari kepribadian seorang guru, apabila guru tersebut telah memiliki kepribadian yang baik maka otomatis dia juga akan berdedikasi terhadap profesinya sebagai guru. Kemampuan mengajar sangat penting dalam mewujudkan kinerja yang profesional karena bagaimana tidak, apabila seorang guru tidak dapat mengajar dengan baik, bagaimana pelajaran yang akan disampaikan dapat diterima oleh anak didiknya. Kedisiplinan sebagai seorang guru yang akan mengajarkan kedisiplinan kepada anak muridnya, seorang guru harus terlebih dahulu memiliki sikap disiplin.

Sedangkan faktor penghambat bagi guru dan tenaga kependidikan untuk melaksanakan nilai-nilai dalam motivasi layanan publik dalam tugas pekerjaannya yaitu faktor internal dari guru itu sendiri seperti kurangnya rasa motivasi dalam mengajar sehingga kinerja yang dihasilkan pun menjadi kurang, motivasi yang tidak ada menyebabkan guru menjadi kurang bersemangat dalam mengajar sehingga kurang efektif dalam proses mengajar. Faktor ini menjadi tantangan dalam mewujudkan kinerja yang profesional dalam diri seorang guru seperti bagaimana guru dan tenaga kependidikan dapat mengatur dirinya sehingga dapat berkomitmen untuk dapat 
membuat dirinya memiliki kinerja yang profesional seperti rasa malas, sikap profesional, tanggung jawab, disiplin. Faktor yang berasal dari luar guru adalah bagaimana dia dapat bekerja sama dengan kepala sekolah dan guru-guru dalam meningkatkan mutu pendidikan, bagaimana berinteraksi dengan peserta didik untuk dapat mengenal kerakter yang berasal dari latar belakang yang berbeda-beda. Faktor eksternal lain berasal dari orangtua siswa atau lingkungan masyarakat, artinya dukungan dari masyarakat akan dapat membantu guru dalam mewujudkan kinerja yang profesional apabila faktor pendukung tidak dapat berjalan dengan baik maka akan menjadi faktor penghambat.

\section{KESIMPULAN}

Berdasarkan hasil penelitian dan pembahasan yang telah diuraikan dapat disimpulkan hasil analisa regresi berganda data kuesioner untuk pengujian hipotesa yaitu terdapat pengaruh mentalitas $(\mathrm{X} 1)$ terhadap motivasi pelayanan $(\mathrm{Y})$ sedangkan kinerja (X2) tidak terdapat pengaruh, sedangkan hasil pengujian hipotesisi secara simultan guru dan tenaga kependidikan memiliki motivasi layanan publik dalam melaksanakan tugas dan wewenangnya sebesar $62,0 \%$.

Faktor yang menjadi pendorong bagi guru dan tenaga kependidikan untuk melaksanakan nilai-nilai dalam motivasi layanan publik dalam tugas pekerjaannya yaitu tingkat pendidikan guru, kepribadian, dedikasi, kemampuan dan kedisiplinan, sedangkan faktor penghambat berasal dari faktor internal yang berasal dari dari guru itu sendiri seperti kurangnya rasa motivasi dalam mengajar sehingga kinerja yang dihasilkan pun menjadi kurang dan faktor eksternal yang berasal dari orangtua siswa atau lingkungan masyarakat, yang artinya dukungan dari masyarakat akan dapat membantu guru dalam mewujudkan kinerja yang profesional.

\section{REFERENSI}

Babakus, Emin, Craven, David W., Johnston, Mark, \& Moncrief, William C. (1996). Examining the Role of Organizational Variables in the Salesperson Job Satisfaction Model. Journal of Personal Selling and Sales Management, Vol. 16, pp. 33-46.

Bachroni, M. (1985). Para Pelajar Sekolah Dasar yang Intelektualnya Superior Ditinjau dari Tingkat Pendidikan dan Jenis Pekerjaan Orangtuanya: Suatu Studi di Sekolah Dasar di Kodya Yogyakarta. Skripsi, Yogyakarta: Fakultas Psikologi UGM.

Boyle. (1997). International Law and the Environment. Oxford: Oxford University Press. Chaizi Nasucha. (2004). Reformasi Administrasi Publik. Jakarta: Alfabeta.

Fahmi, Irham. (2016). Pengantar Manajemen Sumber Daya Manusia. Jakarta. Penerbit: Mitra Wacana Media.

Hardiansyah. (2011). Kualitas Pelayanan Publik (Konsep, Dimensi, Indikator Dan Implementasinya). Yogyakarta: Gava Media.

Hasibuan, Malayu, SP. (2007). Organisasi dan Motivasi. Jakarta. Penerbit: Bumi Aksara. Indra Bastian. (2001). Akuntansi sector publik. Yogyakarta: Fakultas Ekonomi UGM Liosten Riana Roosida Ully Tampubolon, (2014). Manajemen Kinerja Sumber Daya Manusia, Yogyakarta, Andi Ofset, h. 27-28. 
Marliani, R. (2015). Psikologi Industri dan Organisasi. Bandung: CV Pustaka Setia.

McNeese Smith, Donna, (1993). Increasing Employee Productivity, Job Satisfaction and Organizational Commitment. Hospital and Health Services Administration, Vol. 41, No. 2, p.p 160-175.

Michael Armstrong. (2004). Perpormance management, Nyutran: Tugu Publisher. Moenir. (2008). Manajemen Pelayanan Umum Di Indonesia. Jakarta: Bumi Aksara Prawirosentono Suryadi. (1997). Kebijakan Kinerja Karyawan. Yogyakarta, BPFE. Robbin, Stephen P. (1996). Perilaku Organisasi: Konsep, Kontrocersi, Aplikasi, Jilid 1, Edisi Bahasa Indonesia.

Sugiyono. (2004). Statistika Non Parametris Untuk Penelitian. Bandung, Alfabeta.

Thoha, Miftah. (2009). Perilaku Organisasi Konsep Dasar dan Aplikasinya. Jakarta: Raja Grafindo Persada.

Waluyo, M. (2013). Psikologi Industri. Jakarta: Akademia Permata. 